\title{
KEADAAN SANITASI KOLAM RENANG TIRTA YASA DESA MAMBAL KECAMATAN ABIANSEMAL KABUPATEN BADUNG TAHUN 2017
}

\author{
Ni Made Tia Erlinda Sukadewi ${ }^{1}$, Ni Kt. Rusminingsih ${ }^{2}$
}

\begin{abstract}
Tirta Yasa Swimming Pool was opened on 2006, it is located in Mambal Village, Abiansemal District, Badung Regency, it has 3 pools. At the first observation indicate there is not box for food wash, also many garbage in the pool. We interviewed some of customer and the said that they got eye's irritation ifter swim there. The purpose of this research are to know the pool's sanitation condition, to know quality an alchemy of pool's water. Variable that used for this research is pool's sanitation such as water's quality, and also sanitation's facilites that available at Tirta Yasa Swimming Pool. Category of the assesment divide as 3 cathegories such as skors 0-22 is less sanitation, skors >22-44 is enough sanitation, and skors >44-66 is good sanitation. The result of observation of Tirta Yasa Swimming Pool are : from 66 items that has been checked 45 point "Yes" and 21 point "No", it categoried as good sanitation. Recomended to Tirta Yasa Swimming Pool to provide sanitation's facilities and use desinfectan as on rule.
\end{abstract}

Key words : Sanitation public area; swimming pool; poo's sanitation

\section{Pendahuluan}

Sanitasi tempat-tempat umum (public health) adalah suatu usaha pencegahan penyakit yang menitikberatkan kegiatannya pada usaha-usaha kebersihan/ kesehatan tempat-tempat umum dalam melayani masyarakat umum sehubungan dengan aktivitas tempattempat umum tersebut secara fisiologis, psikologis, mencegah terjadinya penularan penyakit atau kecelakaan serta estetika, antarpenghuni, pengguna, dan masyarakat sekitar (1). Kolam renang merupakan suatu usaha bagi umum yang menyediakan tempat untuk berenang, berekreasi, berolah raga, serta jasa pelayanan lainnya yang menggunakan air bersih yang telah diolah (Peraturan Menteri Kesehatan RI No. 061 Tahun 1991). Kolam renang sebagai sarana umum yang ramai dikunjungi masyarakat dapat berpotensi menjadi sarana penyebaran bibit penyakit maupun gangguan kesehatan akibat kondisi sanitasi lingkungan kolam renang yang buruk dan kualitas air kolam renang yang tercemar (2).

Kondisi sanitasi lingkungan kolam renang yang buruk dapat 
disebabkan karena kurangnya pengelolaan kebersihan. Kebersihan lingkungan kolam renang merupakan hal penting yang perlu diperhatikan karena berhubungan dengan aspek kesehatan terutama faktor penularan penyakit di lingkungan kolam renang. Kualitas air kolam renang yang tercemar juga dapat menjadi sarana penyebaran bibit penyakit maupun gangguan kesehatan.

Kolam Renang Tirta Yasa Mambal terletak di Desa Mambal Kecamatan Abiansemal Kabupaten Badung, bekerjasama dengan sekolah-sekolah dasar di wilayah Desa Mambal maupun sekolah menengah atas di wilayah Abiansemal. Kolam Renang Tirta Yasa Mambal juga menyediakan tempat makan, yoga, outbond. Kolam Renang Tirta Yasa Mambal termasuk kolam renang yang mempunyai tipe resirkulasi yaitu air yang kotor disaring dalam filter dan dipompa kembali ke dalam kolam pemandian yang telah bersih. Dari hasil observasi awal air kolam renang terdapat sampah atau bendabenda terapung, tidak terdapat bak cuci kaki pada area kolam renang, dan hasil wawancara beberapa pengunjung menyatakan bahwa pernah mengalami mata merah sehabis berenang.

\section{Metode}

Jenis penelitian yang digunakan dalam penelitian ini adalah jenis penelitian deskriptif yang dilakukan untuk mendeskripsikan atau menggambarkan suatu fenomena yang terjadi di dalam masyarakat dengan menggunakan metode observasional. Waktu dan tempat pada penelitian ini dilakasanakan di Kolam Renang Tirta Yasa Desa Mambal, Kecamatan Abiansemal Kabupaten Badung pada bulan Juni 2017.

Sampel yang diambil dari ketiga kolam renang yang diperiksa secara langsung di lapangan sesuai dengan pemeriksaan dari segi fisik dan kimia sesuai dengan alat dan bahan yang digunakan. Pengumpulan data dalam penelitian ini penulis menggunakan cara observasi atau pengamatan secara langsung, peninjauan langsung dengan formulir pemeriksaan keadaan sanitasi kolam renang dengan menggunakan lembar observasi dan dalam pemeriksaan kualitas air kolam renang menggunakan lembar pemeriksaan, 
stik pH dan komparator. Untuk mengetahui keadaan sanitasi kolam renang Tirta Yasa diajukan 66 item yang berbeda, sedangkan skor untuk kategori dengan interval kelas didasarkan pada buku penganter statistik dengan menggunakan rumus Sturges (3) yaitu kategori memenuhi persyaratan, kurang memenuhi persyaratan, dan tidak memenuhi persyaratan. Tiap item pada observasi sanitasi kolam renang akan diberi skor 1 untuk item "ada" dan skor 0 untuk item "tidak", seluruh item berjumlah 66 sehingga skor tertinggi berjumlah 66 dan skor terendahnya adalah 0. Data yang diperoleh dikelompokkan dan disajikan dalam bentuk tabel sesuai dengan variabel masing-masing.

Keadaan sanitasi kolam renang dibandingkan dengan Peruturan Menteri Kesehatan No.061 Tahun 1991tentang Persyaratan Kesehatan Kolam Renang dan Pemandian Umum dan kualitas air kolam renang dibandingkan dengan Peraturan Menteri Kesehatan RI No.416 Tahun 1990 tentang Syarat-syarat dan Pengawasan Kualitas Air.

\section{Hasil dan Pembahasan}

Kolam Renang Tirta Yasa di buka pada tahun 2006 dengan luas wilayah $2000 \mathrm{~m}^{2}$, yang berlokasi di Banjar Undagi Desa Mambal Kecamatan Abiansemal Kabupaten Badung. Selain kolam renang juga menyediakan tempat makan, yoga, outbond. Kolam Renang Tirta Yasa adalah termasuk kolam renang yang mempergunakan type resirkulasi yaitu air yang kotor disaring dalam filter dan dipompa kembali ke dalam kolam pemandian yang telah bersih, terdapat tiga buah kolam yaitu kolam renang rekreasi (A), kolam renang sport (B), dan kolam renang arus (C).

Jumlah pengunjung di Kolam Renang Tirta Yasa rata-rata 60 orang perhari, dengan tarif yang dikenakan bagi pengunjung yang masuk dengan pembelian karcis sebesar Rp. 15.000,- perorang, beroperasi mulai pukul 09.00-18.00 wita. Adapun jumlah tenaga kerja yang bertugas yaitu 3 orang dengan pembagian tugas 1 orang di loket dan 2 orang di area kolam renang menjaga keselamatan pengunjung sekaligus membersihkan kolam renang.

$$
\text { Pada kolam rekreasi }
$$
kedalaman kolam $80 \mathrm{~cm}$ dengan luas $50 \mathrm{~m}^{2}$ dan volume air 40.000 liter 
sistem penaburan obatnya sebanyak

$2 \mathrm{~kg}$, pada kolam sport (B) kedalaman kolam $150 \mathrm{~cm}$ dengan luas $250 \mathrm{~m}^{2}$ dan volume air 375.000 liter sistem penaburan obatnya sebanyak $2 \mathrm{~kg}$, dan pada kolam arus (C) kedalaman kolam $80 \mathrm{~cm}$ dengan luas kolam $35 \mathrm{~m}^{2}$ dan volume air 28.000 liter sistem penaburan obatnya sebanyak $1 \mathrm{~kg}$ yang dilakukan pada sore hari saat tidak ada pengunjung kolam renang. Bilamana pada air kolam terlihat keruh maka petugas kolam menambahkan campuran PAC (Poly Aluminium Chloride) dengan soda ash sebanyak $2 \mathrm{~kg}$ dimasing-masing kolam.

\section{Sanitasi kolam renang}

Pengukuran keadaan sanitasi Kolam Renang Tirta Yasa dilakukan dengan lembar obervasi berdasarkan komponen yaitu: tempat parkir, loket, bangunan kantor kolam renang, area kolam renang, bak cuci kaki, kamar pancuran bilas, penanganan sampah padat, jamban dan peturasan, tempat cuci tangan, penyediaan air bersih, pembuangan air limbah, gudang bahan kimia, petugas kolam renang, dan pemeliharaan kolam renang.
Sehingga didapatkan hasil yaitu dari 66 item yang di periksa 45 poin "Ya" dan 21 poin “Tidak". Dengan demikian hasil yang diperoleh termasuk dalam kategori keadaan sanitasi baik atau memenuhi persyaratan sesuai dengan Permenkes No.061 Tahun 1991. Adapun item yang tidak memenuhi persyaratan yaitu: tidak adanya bangunan kantor kolam renang, tidak tersedia bak cuci kaki untuk perenang, lantai kolam masih terlihat berlubang, jamban/kamar mandi yang masih terlihat kotor dan lantai kamar mandi yang licin, tempat penampungan air bersih yang tidak tertutup, tidak terdapat gudang bahan kima, tempat sampah yang tidak mempunyai tutup.

2. Kualitas air kolam renang Berdasarkan pemeriksaan kualitas air kolam renang yang dilakukan 7 kali pengukuran dalam 1 minggu didapatkan hasil sebagai berikut: 
a. $\mathrm{pH}$ air kolam renang

Tabel 1.

Hasil Pemeriksaan pH Air Kolam Renang Tirta Yasa

Tahun 2017

\begin{tabular}{lcccc}
\hline No & Hari/Tanggal & Kolam A & Kolam B & Kolam C \\
\hline 1. & Senin/12 Juni 2017 & 2 & 5 & 3 \\
2. & Selasa/13 Juni 2017 & 2 & 5 & 3 \\
3. & Rabu/14 Juni 2017 & 2 & 5 & 2 \\
4. & Kamis/15 Juni 2017 & 3 & 4 & 3 \\
5. & Jumat/16 Juni 2017 & 2 & 5 & 2 \\
6. & Sabtu/17 Juni 2017 & 3 & 4 & 2 \\
7. & Minggu/18 Juni 2017 & 2 & 4 & 3 \\
& $\quad$ Rata-rata & $\mathbf{2}$ & $\mathbf{4 , 5}$ & $\mathbf{2 , 5}$ \\
\hline
\end{tabular}

Berdasarkan tabel di atas rata-rata $\mathrm{pH}$ air kolam renang yaitu kolam renang rekreasi (A) 2, kolam renang sport (B) 4,5 dan kolam renang arus (C) 2,5 ppm, yang artinya keadaan air ketiga kolam renang yaitu asam.
Berdasarkan Peraturan Menteri Kesehatan RI No. 416 Tahun 1990 pH air Kolam Renang Tirta Yasa tidak memenuhi persyaratan yaitu $6,5-8,5$ 
a. Sisa chlor air kolam renang

Tabel 2.

Hasil Pemeriksaan Sisa Chlor Air Kolam Renang Tirta Yasa

Tahun 2017

\begin{tabular}{llccc}
\hline No & Hari/Tanggal & Kolam A & Kolam B & Kolam C \\
\hline 1. & Senin/12 Juni 2017 & 1,0 & 0,6 & 3,0 \\
2. & Selasa/13 Juni 2017 & 1,5 & 0,8 & 3,0 \\
3. & Rabu/14 Juni 2017 & 1,0 & 0,7 & 1,5 \\
4. & Kamis/15 Juni 2017 & 1,5 & 0,7 & 1,5 \\
5. & Jumat/16 Juni 2017 & 0,9 & 0,8 & 3,0 \\
6. & Sabtu/17 Juni 2017 & 0,8 & 0,6 & 1,5 \\
7. & Minggu/18 Juni 2017 & 0,8 & 0,6 & 1,0 \\
& Rata-rata & $\mathbf{1 , 0 ~ p p m ~}$ & $\mathbf{0 , 6} \mathbf{~ p p m}$ & $\mathbf{2 , 0} \mathbf{~ p p m}$ \\
\hline
\end{tabular}

Berdasarkan tabel di atas rata-rata sisa chlor yaitu kolam rekreasi (A) 1,0 ppm, kolam sport (B) 0,6 ppm dan kolam arus (C) 2,0 ppm di karenakan jumlah pengunjung yang berenang di kolam B lebih banyak, semakin banyak pengunjung yang berenang semakin sedikit sisa chlor yang terkandung ditambah lagi sikap pengunjung dalam berenang menggunakan pakaian lengkap. Berdasarkan Peraturan Menteri Kesehatan RI No. 416 Tahun 1990 syarat sisa chlor air kolam renang adalah 0,2-0,5 sehingga sisa chlor dalam air kolam renang tidak memenuhi syarat. 
b. Bau air kolam renang

Tabel 3.

Hasil Pemeriksaan Parameter Bau Air Kolam Renang Tirta Yasa Tahun 2017

\begin{tabular}{clccc}
\hline No & Hari/ tanggal & Kolam (A) & Kolam (B) & Kolam (C) \\
\hline 1. & Senin/12 Juni 2017 & $\sqrt{ }$ & - & $\sqrt{ }$ \\
2. & Selasa/13 Juni 2017 & $\sqrt{ }$ & $\sqrt{ }$ & $\sqrt{ }$ \\
3. & Rabu/14 Juni 2017 & - & - & $\sqrt{ }$ \\
4. & Kamis/15 Juni 2017 & $\sqrt{ }$ & - & $\sqrt{ }$ \\
5. & Jumat/16 Juni 2017 & - & $\sqrt{ }$ & $\sqrt{ }$ \\
6. & Sabtu/17 Juni 2017 & $\sqrt{ }$ & $\sqrt{ }$ & $\sqrt{ }$ \\
7. & Minggu/18 Juni 2017 & - & - & $\sqrt{ }$
\end{tabular}

Keterangan:

$(-) \quad=$ tidak berbau

$(\sqrt{ })=$ berbau

Berdasarkan tabel di atas, dalam persyaratan yang digunakan yaitu 7 kali pemeriksaan yang dilakukan di Peraturan Menteri Kesehatan RI No. masing-masing kolam memperoleh 416 Tahun 1990, dimana kualitas air aroma kaporit yang menyengat kolam renang harus terbebas dari bau khususnya pada kolam arus (C), hal yang mengganggu.

ini menunjukkan tidak sesuai dengan 
c. Kejernihan air kolam renang

Tabel 4.

Hasil Pemeriksaan Parameter Kejernihan Air Kolam Renang Tirta Yasa

Tahun 2017

\begin{tabular}{clccc}
\hline No & Hari/ tanggal & Kolam (A) & Kolam (B) & \multicolumn{2}{c}{ Kolam (C) } \\
\hline 1. & Senin/12 Juni 2017 & - & - & $\sqrt{ }$ \\
2. & Selasa/13 Juni 2017 & $\sqrt{ }$ & $\sqrt{ }$ & $\sqrt{ }$ \\
3. & Rabu/14 Juni 2017 & $\sqrt{ }$ & - & $\sqrt{ }$ \\
4. & Kamis/15 Juni 2017 & $\sqrt{ }$ & $\sqrt{ }$ & $\sqrt{ }$ \\
5. & Jumat/16 Juni 2017 & $\sqrt{ }$ & $\sqrt{ }$ & $\sqrt{ }$ \\
6. & Sabtu/17 Juni 2017 & - & - & $\sqrt{ }$ \\
7. & Minggu/18 Juni 2017 & - & - & $\sqrt{ }$
\end{tabular}

Keterangan :

$(-) \quad=$ tidak jernih

$(\sqrt{ })=$ jernih

Berdasarkan tabel di atas, dari 7 kali pemeriksaan yang dilakukan dimasing-masing kolam memperoleh hasil air masih terlihat keruh, hal ini menunjukkan tidak sesuai dengan persyaratan yang digunakan yaitu Peraturan Menteri Kesehatan RI No. 416 Tahun 1990, dimana kejernihan air dilihat jelas dari tepi kolam pada jarak lurus 7 meter. 
d. Benda terapung air kolam renang

Tabel 5.

Hasil Pemeriksaan Parameter Benda Terapung Air Kolam Renang Tirta Yasa Tahun 2017

\begin{tabular}{ccccc}
\hline No & \multicolumn{1}{c}{ Hari/ tanggal } & Kolam (A) & Kolam (B) & \multicolumn{2}{c}{ Kolam (C) } \\
\hline 1. & Senin/12 Juni 2017 & $\sqrt{ }$ & - & $\sqrt{ }$ \\
2. & Selasa/13 Juni 2017 & - & - & $\sqrt{ }$ \\
3. & Rabu/14 Juni 2017 & $\sqrt{ }$ & $\sqrt{ }$ & $\sqrt{ }$ \\
4. & Kamis/15 Juni 2017 & - & - & $\sqrt{ }$ \\
5. & Jumat/16 Juni 2017 & - & $\sqrt{ }$ & $\sqrt{ }$ \\
6. & Sabtu/17 Juni 2017 & $\sqrt{ }$ & - & $\sqrt{ }$ \\
7. & Minggu/18 Juni 2017 & $\sqrt{ }$ & $\sqrt{ }$ & $\sqrt{ }$ \\
\hline
\end{tabular}

Keterangan :

$(-) \quad=$ tidak ada benda terapung

$(\sqrt{ })=$ ada benda terapung

Berdasarkan tabel di atas dari 7 kali pemeriksaan yang dilakukan dimasingmasing kolam memperoleh hasil terdapat benda-benda terapung dimasing-masing kolam renang, hal ini menunjukkan tidak sesuai dengan persyaratan yang digunakan yaitu Peraturan Menteri Kesehatan RI No. 416 Tahun 1990, dimana air kolam renang terbebas dari benda terapung

\section{Pembahasan}

a. Sanitasi Kolam Renang

Kolam renang adalah suatu usaha bagi umum yang menyediakan tempat untuk berenang, berekreasi, dan berolahraga serta jasa pelayanan lainnya menggunakan air bersih yang telah diolah(4). kolam renang yang ideal adalah kolam renang yang senantiasa memenuhi syarat keamanan, kebersihan, dan kenyamanan. Suatu kolam renang diharapkan mampu memberikan kenyamanan bagi para pengunjung namun tetap harus mengedepankan faktor keamanan, terutama untuk semua fasilitas penunjang yang berada di dalam area kolam renang. Selain itu, aspek kebersihan juga merupakan hal terpenting untuk 
diperhatikan karena berkaitan erat dengan aspek kesehatan khususnya faktor penularan penyakit. Penyakitpenyakit yang dapat ditularkan di kolam renang meliputi semua penyakit food and water borne disease, seperti penyakit mata, penyakit kulit, penyakit kuning (hepatitis), dan penyakit yang berhubungan dengan pencernaan(2).

Menurut Peraturan Menteri Kesehatan RI No. 061 Tahun 1991Tentang Persyaratan Kesehatan Kolam Renang dan Pemandian Umum, suatu kolam renang harus memenuhi persyaratan kesehatan lingkungan kolam renang seperti persyaratan umum, persyaratan tata bangunan, persyaratan kontrusi bangunan, persyaratan kelengkapan kolam renang, persyaratan bangunan dan fasilitas sanitasi kolam renang. Berdasarkan hasil yang sudah didapatkan sanitasi kolam renang memperoleh 45 poin yang setelah di bandingkan dengan Permenkes No.061 Tahun 1991 sehingga dapat dikatakan memenuhi persyaratan. Tetapi beberapa fasilitas kolam renang tidak memenuhi persyatan yaitu: tidak adanya kantor untuk kolam renang yang seharusnya harus terdapat kantor sehingga dapat menjadi tempat meletakkan laporanlaporang maupun ruang pengawasan kolam renang.

Beberapa lantai kolam renang yang ada terdapat lubang atau keramik yang retak sehingga dapat membahayakan para perenang selain itu lantai yang berlubang akan sulit untuk dibersihkan, maka diperlukan perbaikan terhadap lantai kolam renang sehingga dapat memberikan rasa aman dan nyaman bagi para perenang dan lantai juga mudah untuk dibersihkan.

Tempat cuci kaki merupakan sarana yang penting bagi kolam renang. Suatu kolam renang harus memiliki tempat mencuci kaki bagi para perenang sebelum masuk ke dalam kolam renang, karena apabila tidak membersihkan kaki terlebih dahulu di tempat cuci kaki yang telah disediakan akan dapat menyebabkan air kolam renang menjadi kotor dan keruh, selain itu juga dapat mempengaruhi kualitas air kolam renang. Maka dari itu kolam renang seharusnya menyediakan bak cuci kaki yang terisi air agar dapat berfungsi sebagai barrier utuk meminimalkan masuknya kotoran 
dari luar ke dalam kolam renang yang dapat terbawa oleh kaki pengguna kolam renang (5).

Penanganan sampah yang baik dapat menciptakan suasana yang bersih serta memberikan kenyamanan bagi para pengujung. Tempat sampah yang tersedia di Kolam Renang Tirta Yasa sudah memenuhi syarat kuantitas (tersedia di tempat-tempat kegiatan) dan diangkut setiap hari oleh truk pengangkut sampah, namun tempat sampah yang disediakan tidak memiliki tutup sehingga jika dipandang dari sudut sanitasi sangat tidak baik karena dapat menyebabkan penyebaran bibit penyakit. Selain itu jika dipandang dari segi estetika sangat tidak baik, maka diperlukan pengawasan dan pemeliharan sarana sanitasi terhadap penanganan sampah maupun tempat penampungan sampah agar dapat menjaga citra kolam renang dan mencegah penyebaran bibit penyakit (6). Kondisi tempat sampah yang tidak tertutup, secara tidak langsung dapat berpengaruh terhadap kualitas air kolam renang karena dapat mengundang hewan pengerat seperti tikus yang dapat menyebabkan pencemaran mikrobiologis pada air kolam renang melalui kontaminasi dari kotorannya (5). Maka disarankan untuk menyediakan penutup tempat sampah agar terhindar dari tikus, lalat dan kecoa yang dapat mengkontaminasi air.

Tersedianya jamban atau toilet sangat penting bagi suatu kolam renang. Penyediaan jamban atau toilet di kolam renang tirta yasa dari segi kuantitas telah sesuai dengan persyaratan yaitu sudah tersedia 1 jamban/toilet untuk 40 orang wanita dan 1 jamban/ toilet untuk 60 orang pria serta jamban/toilet pria dan wanita sudah terpisah, tetapi jamban/toilet yang disediakan masih dalam keadaan yang kotor, atap pada toilet yang rapuh dan terpadat sarang laba-laba, serta dinding jamban/toilet berkelupas. Sebaikknya perlu dilakukan perbaikan terhadap jamban/toilet dan melakukan upaya pembersihan atau pemeliharaan kebersihan secara rutin agar tidak menjadi perkembangbiakan kuman dan penyakit serta pengunjung kolam renang akan merasa nyaman (6).

Kamar atau pancuran yang disediakan sudah terpisah antar pria dan wanita serta pancuran bilas yang 
disediakan cukup banyak. Tetapi keadaan yang kotor sangat mempengaruhi kenyaman pengunjung kolam renang, selain itu lingkungan yang kotor dapat mengundang kecoa dan tikus yang dapat menyebabkan penyakit dan menganggu kenyamanan, serta banyaknya coretan ataupun lumut pada dinding pancuran bilas sangat mengganggu estetika. Maka diperlukan meningkatkan upaya pemeliharan pancuran bilas dan meningkatkan kebersihan agar pengunjung kolam renang merasa nyaman dan tidak terjadi penularan penyakit.

Tempat cuci tangan/washtafel adalah sarana yang sangat penting bagi pengunjung maupun petugas kolam renang. Menurut Permenkes No. 061 tahun 1991 tempat cuci tangan terletak di tempat yang mudah dijangkau dan berdekatan dengan jamban petursan dan kamar ganti pakaian serta dilengkapi dengan sabun, pengering tangan dan cermin. Tidak tersedianya tempat cuci tangan di kolam renang tirta yasa mengakibatkan sulitnya pengunjung dan petugas kolam renang untuk mencuci tangan.
Mencuci tangan sangat penting dilakukan untuk mencegah penyebaran penyakit masuk kedalam tubuh melalui telapak tangan yang terkontaminasi oleh kuman maupun zat berbahaya, sehingga penyediaan tempat cuci tangan sangat disarankan untuk mempermudah pengunjung untuk mencuci tangan.

Penyediaan air bersih di Kolam Renang Tirta Yasa diperoleh dari air pegunungan yang di suplai oleh pihak swasta untuk pengisisan kolam renang, sedangkan untuk aktifitas mandi dan bilas diperoleh dari sumur yang di tampung. Bak penampungan air bersih tidak memiliki tutup sehingga dapat menjadi perkembangbiakan nyamuk serta tercampur dengan air hujan. Maka daripada itu tempat penampungan air bersih sebaiknya di tutup.

Di kolam renang tirta yasa tidak tersedia gudang bahan kimia, bahan kimia yang digunakan seperti: bubuk Chlorin, poly aluminium chloride, HCL, soda ash yang berguna untuk membunuh kuman, mengikat kotoran serta menetralkan $\mathrm{pH}$ kolam renang, tetapi semua bahan diletakkan menjadi satu di belakang bagunan dan tidak tertutup. Menurut 
Permenkes No.016 Tahun 1991

kolam renang harus memiliki gudang tempat penyimpanan bahan kimia dan penempatan kasium hipoklorit $\left(\mathrm{Ca}(\mathrm{Cl} 0)_{2}\right.$ harus terpisah dengan aluminium sulfat atau bahan-bahan kimia lainnya. Tersedianya gudang untuk menyimpan bahan kimia yang diperlukan untuk proses pemeliharaan kolam renang sangat penting, hal ini bertujuan agar bahan kimia yang digunakan dapat terlindungi dan aman dari jangkauan anak-anak.

Pemeliharan kolam renang Tirta Yasa di bersihkan setiap 2 kali sehari yaitu pagi dan sore hari, alat yang digunakan untuk membersihkan area kolam renang seperti jaring pembersih sampah, vacuum set trolley, test kit, sapu. Tetapi pemeriksaan kadar clorin dan $\mathrm{pH}$ masih jarang dilakukan sehingga kadar chlorin dan $\mathrm{pH}$ air tidak terpantau. Pengawasan kualitas air kolam renang dilakukan dengan melakukan pemeriksaan terhadap beberapa parameter kualitas air baik secara rutin maupun berkala. Pengawasan dilakukan untuk memantau kulitas air kolam renang agar selalu dalam keadaan aman jika digunakan oleh pengguna kolam renang.

Fasilitas lain yang terdapat di kolam renang Tirta Yasa yaitu sudah tersedianya kotak P3K yang mudah terjangkau dan lengkap dengan obatobatan, tersedia pertolongan bagi perenang seperti tali dan pelampung, tersedia tempat duduk atau gazebo yang cukup bagi pengunjung kolam renang, tersedia loker atau tempat penyimpanan baju yang aman, serta terdapat peraturan-peraturan yang tertempel di beberapa lokasi yang mudah terlihat sehingga memudahkan bagi para pengunjung untuk memperoleh informasi.

1. Kualitas Air kolam renang

$\begin{array}{rlr}\text { Kolam } & \text { Renang Tirta } & \text { Yasa } \\ \text { merupakan } & \text { kolam renang } & \text { yang } \\ \text { banyak } & \text { dimanfaatkan } & \text { oleh }\end{array}$
masyarakat lokal maupun domestik untuk menjadikan sebagai tempat berenang, tempat rekreasi dan berolahraga. Perlakuan penggantian ai bersih dilakukan 2 tahun sekali dengan menggunakan air isi ulang pada suplyer tetap, untuk menjaga kualitas air kolam renang harus memenuhi syarat kesehatan baik dari segi fisik kimia maupun bakteriologi. Persyaratan air kolam renang yang 
terdapat dalam Peraturan Menteri Kesehatan Republik Indonesia No.416/Menkes.Per/IX/1990 tentang syarat-syarat dan pengawasan kualitas air seperti air minum, air bersih, air kolam renang dan air pemandian umum.

\section{a. $\mathrm{pH}$ air kolam renang}

Sesuai dengan hasil yang pemeriksaan $\mathrm{pH}$ air kolam renang Tirta Yasa yang dilakukan selama satu minggu didapatkan yaitu kolam rekreasi (A) 2, kolam sport (B) 4,5, kolam arus (C) 2,5 dan menunjukkan hasil yang tidak memenuhi persyaratan kualitas air dari segi parameter kimia, pada parameter $\mathrm{pH}$ yang terdapat dalam Peraturan Menteri Kesehatan Republik Indonesia

No.416/Menkes/Per/IX/1990

mengenai syarat-syarat dan pengawasan kualitas air kolam renang yang menyebutkan bahwa parameter $\mathrm{pH}$ kadar yang diperbolehkan adalah 6,5-8,5.

Rendahnya nilai $\mathrm{pH}$ air pada kolam renang kemungkinan dapat disebabkan karena adanya pertambahan bahan-bahan organik dalam air kolam renang yang akan membebaskan $\mathrm{CO}_{2}$ dan menyebabkan penguraian sehingga nilai $\mathrm{pH}$ menjadi turun menuju suasana asam. Bahan-bahan organik dalam air kolam renang tersebut dapat berasal dari keringat maupun urine yang dihasilkan oleh para pengunjung. Dampak yang dapat disebabkan karena rendahnya $\mathrm{pH}$ air kolam renang yaitu dapat menyebabkan gangguan kesehatan seperti mata terasa terbakar, kulit terasa kering dan gatal, selain itu juga menyebabkan pemakaian klorin yang akan meningkat, pakaian renang akan mudah rusak, bahan yang terbuat dari logam terutama besi akan cepat berkarat, dan akan merusak dasar keramik serta mempercepat tumbuhnya lumut (7)

Semakin tinggi $\mathrm{pH}$ air dapat mengakibatkan proses klorinasi tidak efektif, karena 90\% dari asam hipoklorit itu akan mengalami ionisasi menjadi ion hipoklorit. Dengan demikian khasiat desinfektan yang mengalami chlorin menjadi lemah atau kurang sehingga masih terdapat bakteri dalam air kolam renang. Chlorin dapat bekerja secara efektif sebagai desinfektan jika berada dalam air dengan $\mathrm{pH}$ 7(8). 
Upaya yang dapat dilakukan untuk menetralkan $\mathrm{pH}$ air dalam kolam renang pada penelitian (7), adalah dengan menggunakan bahan kimia seperti HCL maupun soda ash. HCL digunakan untuk menetralkan $\mathrm{pH}$ air yang bersifat basa, sedangkan soda ash digunakan untuk menetralkan $\mathrm{pH}$ air yang bersifat asam. Penggunaan bahan kimia tersebut tidak akan memberikan efek berbahaya terhadap kesehatan apabila dosis penggunaanya sesuai dan nilai $\mathrm{pH}$ dalam air kolam renang harus selalu terjaga dalam kisaran 7,2-8,0.

b. Sisa chlor air kolam renang

Sisa chlor merupakan kandungan chlor setelah adanya proses klorinasi yang bertujuan untuk membunuh bakteri, chlor aktif bersifat toksik (racun) bagi kuman, dan keaktifannya tergantung pada $\mathrm{pH}$, suhu kontak dan konsentrasi zat kimia. Chlorin dalam air akan berubah menjadi asam klorida, zat ini kemudian di netralisasi oleh sifat basa dan air sehingga akan terurai menjadi ion hydrogen dan ion hipoklorit. Chlorin sebagai desinfektan terutama bekerja dalam bentuk asam hupoklorit ( $\mathrm{HOCl})$ dan sebagian kecil dalam bentuk ion hipoklorit (OCl-). Chlorin dapat bekerja dengan efektif jika berada dalam air dengan $\mathrm{pH}$ sekitar 7, jika $\mathrm{pH}$ air lebih dari 8,5 maka $90 \%$ dari asam hipoklorit itu akan mengalami ionisasi menjadi ion hipoklorit. Dengan demikian khasiat desinfektan yang mengalami chlorin menjadi lemah atau kurang (8).

Sesuai dengan hasil pemeriksaan sisa chlor pada air kolam renang Tirta Yasa dengan waktu pemeriksaan 7 kali kali selama seminggu dan dilakukan pada sore hari didapatkan hasil sisa chlor pada kolam rekreasi sebesar 1,0 ppm, kolam sport sebesar 0,6 ppm dan kolam arus sebesar 2,0 ppm. Hal ini menunjukkan bahwa sisa chlor air kolam renang Tirta Yasa tidak memenuhi persyaratan kualitas air dari segi parameter kimia, pada marameter sisa chlor yang terdapat dalam Peraturan Menteri Kesehatan Republik Indonesia No.416/Menkes/Per/IX/1990 tentang syarat-syarat dan pengawasan kualitas air kolam renang yang menyebutkan bahwa parameter sisa chlor yang diperbolehkan adalah 0,20,5 ppm. 
Kadar sisa chlor yang terlalu tinggi dalam air dapat menyebabkan gangguan kesehatan berupa keluhan yang dialami oleh pengguna kolam renang, efek kesehatan yang umum muncul atau dirasakan oleh seseorang sesaat setelah terpapar chlorin antara lain adalah iritasi saluran napas, dada sesak, gangguan pada tenggorokan, batuk, iritasi pada kulit, dan iritasi pada mata (2). Tingkat keparahan dari masingmasing efek tersebut bergantung pada rute paparan, dosis paparan, dan durasi paparan. Rute paparan atau masuknya zat kimia dalam air (termasuk chlorin) ke tubuh pengguna kolam dapat terjadi melalui inhalasi, ingesti, dan kontak kulit (5).

Apabila sisa chlor yang terkandung pada air kolam renang kurang dari 0,2 tidak efektif untuk membunuh kuman atau mikroba yang dapat merugikan perenang. Secara perhitungan kasar, kolam renang membutuhkan \pm 600 gram chlorin serbuk granula untuk setiap 50.000 liter air setiap 2 minggu sekali. Dengan melakukan perhitungan kasar untuk menentukan jumlah kaporit yang diperlukan, maka memperoleh hasil perhitungan pada kolam rekreasi dengan volume air 40.000 liter diberikan 480 gram, kolam sport dengan volume air 375.000 liter diberikan 4.500 gram, dan kolam arus dengan volume air 28.000 liter diberikan 336 gram kaporit yang dilakukan setiap 2 minggu sekali.

Pencegahan penyebaran penyakit melakui kolam renang dapat diminimalkan bila dilakukan pengolahan kualitas air dengan baik. Pengukuran jumlah kaporit yang diberikan pada kolam renang dapat diukur melalui Jar Test dan DSC (Daya Sergap Chlor) lalu didapatkan sisa chlor sesuai standar Permenkes RI No.416/MENKES/PER/IX/1990 yaitu dengan standar minimum 0,20,5 .

c. Bau air kolam renang

Pada hasil pemeriksaan yang diperoleh tentang parameter bau, air kolam renang Tirta Yasa yang diperiksa secara manual dengan cara menggunkan menciuman dari peneliti dan rekan-rekan peneliti yang dilakukan 7 kali pemeriksaan dalam seminggu hasilnya positif atau tidak terbebas dari bau kaporit yang menyengat. Hal ini menunjukkan 
hasil yang diperoleh tidak sesuai dengan persyaratan Peraturan Menteri Kesehatan Republik Indonesia

No.416/Menkes/Per/IX/1990 pada kualitas air kolam renang dari segi fisik yaitu parameter bau yang terdapat dalam ketiga air kolam renang Tirta Yasa. Hal tersebut dikarenakan petugas kolam renang membubuhkan kaporit $2 \mathrm{~kg}$ setiap hari kedalam kolam. Penambahan chlor secara kurang tepat menimbulkan bau, rasa pahit dan dapat mengganggu estetika lingkungan sekitar. Karena banyaknya penggunaan chlorin di lapangan dalam dosis yang berlebihan sering terjadi pelepasan gas chlorin. Gas chlorin adalah gas berwarna hijau dengan bau yang sangat menyenga (7). Maka dari itu upaya yang dapat dilakukan agar bau chlorin agar tidak menyengat yaitu penggunaan bubuk kaporit yang sesuai dengan takaran sehingga pengguna kolam renang merasa nyaman saat berenang.

d. Kejernihan air kolam renang

Berdasarkan hasil pengamatan tentang parameter kejernihan, air kolam renang Tirta Yasa yang diperiksa secara manual dengan cara menggunakan penglihatan dari peneliti dan rekan-rekan peneliti dengan melihat piringan yang diletakkan di dasar kolam dengan jarak $7 \mathrm{~m}$, yang dilakukan 7 kali pemeriksaan dalam seminggu hasil yang diperoleh kolam arus terlihat jernih dikarenakan pada kolam arus jarang pengunjung yang menggunkannnya. Sedangkan kolam rekreasi dan kolam sport air masih terlihat keruh dikarenakan banyak pengunjung yang menggunakan kolam tersebut. Hal ini menunjukkan hasil yang diperoleh tidak memenuhi persyaratan kualitas air kolam renang dari segi fisik pada parameter kejernihan yang terdapat pada Peraturan Menteri Kesehatan Republik Indonesia No.416/Menkes/Per/IX/1990 tentang syarat-syarat dan pengawasan kualitas air kolam renang yang menyebutkan bahwa parameter kejernihan harus bebas dari kekeruhan/airnya harus jernih.

Dari hasil wawancara terhadap salah satu petugas kolam renang mengatakan warna air kolam renang cepat berubah menjadi kehijauan dan dinding kolam renang cepat 
mengalami pertumbuhan lumut saat musim hujan. Hal tersebut dikarenakan suhu air kolam renang terhadap air hujan berbeda sehingga dapat mempengaruhi proses kaporit di dalam air serta keadaan air kolam renang akan menjadi asam dan mempercepat pertumbuhan lumut pada dinding kolam renang, maka dari itu penggunaan bahan koagulan seperti Poly Aluminuim Clorida dapat berguna untuk mengikat kotoran dalam air kolam renang termasuk alga atau lumut, serta penggunaan kaporit yang tepat dapat membunuh kuman dan air tidak menjadi keruh akibat penggunaan kaporit yang berlebihan.

e. Benda terapung air kolam renang

Berdasarkan hasil pengamatan benda terapung pada air kolam renang Tirta Yasa yang diperiksa secara manual dengan cara menggunakan penglihatan dari peneliti dan rekan-rekan peneliti yang dilakukan 7 kali dalam seminggu didapatkan hasil adanya benda terapung di semua kolam renang seperti terlihat helai rambut pengunjung yang mengambang di pinggiran kolam, serpihan kayu-kayu kecil, dedaunan kering, debu yang mengambang serta dahak dari pengguna kolam renang. Dengan adanya hal tersebut dapat mengganggu kenyamanan pengunjung dan mengakibatkan kurangnya nilai estetika.

Pada pinggiran kolam renang terdapat tumbuhan yang merambat yang berfungsi sebagai peneduh, selain itu terdapat pohon-pohon besar di luar area kolam renang yang apabila angin berhembus kencang maka dedaunan yang kering dapat terbang terbawa angin dan jatuh di kolam renang.

Maka daripada itu upaya yang dapat dilakukan yaitu selalu membersihkan air kolam renang minimal 2 kali sehari maupun menyarankan kepada pengunjung kolam renang untuk memakai pelindung kepala agar tidak ada helai ramput yang jatuh di air kolam renang.

\section{Simpulan dan Saran}

Berdasarkan pembahasan yang dilakukan terhadap hasil penelitian maka penulis dapat menarik kesimpulan sebagai berikut: (1) Keadaan sanitasi Kolam Renang Tirta Yasa memperoleh skor 45 dari 
66 item yang diperiksa dengan kategori keadaan sanitasi baik. (2) Fasilitas sanitasi yang tersedia di Kolam Renang Tirta Yasa yaitu: terdapat kamar pancuran bilas, toilet/jamban, tempat sampah, penyediaan air besih, alat pemeliharaan kolam renang. Yang tidak tersedia yaitu: gudang bahan kimia, bak cuci kaki dan wastafel/tempat cuci tangan. (3) Kualitas air kolam renang pada parameter kimia yaitu: $\mathrm{pH}$ air didapatkan kolam rekreasi 2, kolam sport 4,5, dan kolam arus 2,5 bahwa air kolam renang tirta yasa tidak memenuhi syarat. Sisa chlor air didapatkan kolam rekreasi 1,0 ppm, kolam sport 0,6 ppm dan kolam arus 2,0 ppm bahwa air kolam renang tidak memenuhi syarat. Serta pada parameter fisik (bau, kejernihan, benda terapung) didapatkan bahwa air kolam renang tirta yasa tidak memenuhi persyaratan yang telah ditentukan karena masih ada benda terapaung, ada bau, dan tidak jernih.

Adapun saran yang dapat disampaikan Untuk lebih meningkatkan kualitas kolam renang Tirta Yasa dari sudut sanitasi, maka disarankan bagi pengelola kolam renang agar selalu menjaga kebersihan kamar mandi dan pancuran bilas, memperbaiki lantai kolam renang yang berlubang, menyediakan fasilitas sanitasi seperti tempat cuci tangan, tempat sampah yang tertutup, menyediakan kantor kolam renang, serta menyediakan gudang penyimpanan bahan kimia. Memberikan desinfektan sesuai dengan takaran yang dianjurkan dan memeriksa kembali kualitas air kolam renang baik fisik maupun kimia sebelum di gunakan.

\section{Daftar Pustaka}

1. Suyono B. Ilmu Kesehatan Masyarakat Dalam Konteks Kesehatan Lingkungan. Jakarta: EGC; 2010.

2. Esma N. Tinjauan Sanitasi Lingkungan Kolam Renang, Kadar Sisa Khlor, dan Keluhan Iritasi Mata Pada Perenang di Kolam Renang Umum Kota Semarangtle. Semarang; 2015.

3. Sugiyono. Metode Penelitian Kuantitatif Kualitatif dan R\&D. Bandung: : ALFABETA; 2012.

4. Mukono. Higiene Sanitasi 
Hotel dan Restoran. :

Airlangga. Surabaya:

Umum. Surabaya: Duatujuh;

University Press; 2004.

2012.

5. WHO. Guidelines For Safe

7. Suryatni S. Tinjauan Sanitasi

Recreational Water

Environment Volume 2

Swimming Pools And Similar

Environments. Volume 2.

Switerland: WHO Press.; Kolam Renang Dan Tingkat Kenyamanan Pengunjung di Kolam Renang Tirta Bayu Kuta Utara Badung. Badung: Kementerian Kesehatan RI.; 2016.

2006.

8. Elly A. Kadar Sisa Chlor dan

6. Suparlan. Penganter

Pengawasan Hygiene-Sanitasi

Tempat-Tempat Umum-

Wisata Dan Usaha Untuk Kandungan E.Coli Air PT Dream Succes Airindo (DAS). [Surabaya]: Universitas Airlangga.; 2007. 